\section{EU will gain from funding eastern European centres of excellence}

Sir - The differences between standards of research, defence and industry in European Union (EU) member states and other central or eastern European countries are undeniable. These 'gaps' have led some people to argue that, if the latter countries join the EU, the lack of cohesion between them and the existing members could destroy the whole structure. Although this point of view could be challenged, we propose a practical solution: the systematic upgrading of research facilities in central and eastern European countries.

Before 1989, central and eastern European countries could not contribute properly to the development of advanced research equipment and devices going on in the West. Eleven years after the fall of the Berlin wall, the former communist countries have made only a little headway in commercial production and purchase of high-tech scientific equipment. Even in the countries that are making most rapid progress and have developed the skills to make non-serial high-tech equipment, the main obstacle to attaining excellence in experimental research remains either the insufficient performance of research facilities, or the lack of them altogether. This, together with low salaries, reduces the appeal of institutes in the region.

There are two main problems with upgrading. One is that only EU member states have access to the structural funds dedicated to 'cohesion building'. The other is that many experts and decisionmakers do not consider that this type of assistance should cover quality of scientific research. They fear that money will go to unqualified people just because they are in a poor country, and the funding will still be unlikely to bring them up to a useful standard. Yet this presumed incompatibility between cohesion and excellence is more apparent than real: Margaret Sharp has pointed out (Research Policy 27, 569; 1998) that the concept of excellence puts emphasis on the EU as a whole, and cohesion is about helping poorer countries and regions to catch up. This is a pertinent analysis, identifying the two concepts as complementary. The next step, of course, is specific action to achieve cohesion.

One way of dealing with the issue is the recent action of the European Commission in identifying centres of excellence in the pre-accession countries. It seems quite likely that the majority of the 34 centres could receive long-term funding to establish them as European or regional attractors for research and training activities, and as poles of local economic development. Such funds should be used mostly for upgrading research facilities. The European Council and the European Commission now need to stimulate the growth and consolidation of the selected centres via the structural funds of the EU.

The upgrade of the most promising research facilities requires a coordination mechanism: for example, financing could be shared along the lines of one national or regional euro for every European one. If some centres of excellence could serve several neighbouring countries, consortia could be formed between countries or regions to share the cost.

Simeon Anguelov (former Bulgarian ambassador to France $)^{\star}$, Norbert Kroo $\dagger$, Pierre Lasserre‡, Pierre Papon\$

*79 Quai André Citroën, Paris 75015, France †Hungarian Academy of Sciences, Roosevelt sq. 9 , H-1051 Budapest, Hungary

$\ddagger U N E S C O$ Venice Office-Regional Office for S\&T in Europe, 1262/A Dorsoduro, 30123-Venice, Italy \$Ecole supérieure de physique et chimie industrielles, 10 rue Vauquelin, 75005 Paris, France

\section{Spain is a closed culture to foreign researchers}

Sir - We wish to add a foreigner's perspective on the current debate (for example, see Nature 407, 659; 2000 and $410,14 ; 2001)$ about the Spanish research environment, in which we have each spent more than five years.

In a policy at odds with the rest of the EU, posts for non-EU nationals are simply not available in Spain's huge public sector. As for EU nationals, those with a degree from a country where the state does not regulate the profession of lecturer or researcher cannot apply for serious posts in Spain without either having three years' experience in their country of study or 'homologating' their degrees - having them approved by the Spanish authorities.

The homologation procedure is both arbitrary and extremely inefficient. Degrees from EU and other countries are homologated only after years of administrative stonewalling, if at all. One of us, for example, has published more than 100 papers in international publications, yet spent four years trying unsuccessfully to get homologation for an honours degree in mathematics from the University of Cambridge. This example is illustrative. The tiny number of foreign researchers in Spain compared with the rest of the EU suggests lack of compliance with EU directives on free movement of labour.

The issues of consistent government underinvestment and of closed-shop practices - due in large part to an uninhibited culture of nepotism and patronage ill-befitting a democratic, developed country — have already been raised in the Opinion and Correspondence referred to above and in other articles. But the way these issues affect Spanish research merits further clarification.

Government underinvestment leads to many researchers spending 10 or more years on poorly paid, short-term (one year or less) contracts or grants, just to reach the starting salary of a public-sector school teacher. About half the lecturers in Spain are 'asociados' on one-year contracts; many full-time asociados earn little more than 14,000 euros (US\$12,900) a year. Generally speaking, only short-term contracts and grants are available to foreigners, and these are mainly restricted to EU nationals.

Closed-shop practices can lead to posts being treated as largesse and $\mathrm{PhDs}$ becoming little more than probationary employment periods, lasting for six years or even more. This encourages a drift towards little or no supervision, little research of any value, and the award of a $\mathrm{PhD}$ becoming a formality for those who go the distance. On the way, $\mathrm{PhD}$ students, and others on short-term contracts, may have to work on all manner of tasks, a situation exacerbated by slack financial controls. Not surprisingly, a large number of $\mathrm{PhDs}$ are abandoned. In this climate, foreigners who come to study for a $\mathrm{PhD}$ may end up going home without one.

Such a deep-rooted endogamic culture might be broken only by drastic measures such as prohibiting the move from a doctorate to a post in the same institution and requiring a minimum number of international publications for higher-level posts. Although it is important to entice Spanish researchers working overseas to return (currently it is very difficult for them to do this), focusing on this issue instead of on the issue of researcher mobility in general — draws attention away from the root of the problem, that of impermeability to external candidates.

It is ironic that the Spanish government is pressing for more of this mobility in the context of the next EU research programme, when it has so far made little attempt to put its own house in order. It is time the many dedicated, hard-working and talented researchers in Spain were provided with a system and a budget under which they can produce quality results. Simon Pickin

IRISA, Campus de Beaulieu, 35042 Rennes, France Other signatories to this letter:

Peter Breuer, Carlos III University, Spain

Gennady Fiksman, Nortel Networks, Spain

Salvador López Mendoza, Autonomous National University of Mexico

Amparo López Gaona, Autonomous National University of Mexico Carlos Sánchez Tarnawiecki, Fundacio Bosch i Gimpera, Peru 